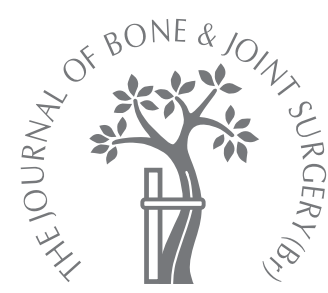

K. A. Lefaivre,

A. J. Starr,

B. P. Barker,

S. Overturf,

C. M. Reinert

From the University

of Texas

Southwestern, Texas,

United States
- K. A. Lefaivre, MD, MSc, FRCSC, Assistant Professor, Orthopaedic Surgeon

Department of Orthopaedic Surgery

University of British Columbia VGH Research Pavilion, 110-828 West 10th Avenue, Vancouver, British Columbia, Canada V5Z 1 L8.

A. J. Starr, MD, Associate Professor, Orthopaedic Surgeon

S. Overturf, MD, Resident C. M. Reinert, MD, Professor

Orthopaedic Surgeon Department of Orthopaedic Surgery

University of Texas

Southwestern Medical Center, 5323 Harry Hines Boulevard, Room G8.323, Dallas, Texas 75390-8870, USA

B. P. Barker, MD, Orthopaedic Surgeon

1157 N 300 W, Provo, Utah 84604, USA

Correspondence should be sent to $\operatorname{Dr}$ K. A. Lefaivre; e-mail: kellylefaivre@hotmail.com

(C)2009 British Editorial Society of Bone and Joint Surgery doi:10.1302/0301-620X.91B9. $22093 \$ 2.00$

$J$ Bone Joint Surg $[\mathrm{Br}]$ 2009;91-B:1201-7. Received 20 November 2008 Accepted after revision 7 May 2009

\title{
Early experience with reduction of displaced disruption of the pelvic ring using a pelvic reduction frame
}

We describe our early operative experience with a new pelvic reduction frame and the standard of reduction of fractures of the pelvic ring which we achieved in the first 35 consecutive patients, with $\mathbf{3 4}$ acute fractures and one nonunion. The pre-operative and immediate post-operative radiographs were measured, using two methods, to find the maximum radiological displacement of the fracture and the quality of the reduction according to the criteria of Tornetta and Matta.

There were 19 vertical shear fractures and 16 compression injuries. The mean age of the patients was 33.5 years ( 10 to 59 ) and mean delay to surgery was 4.6 days ( 0 to 16 ) in the 34 acute injuries. The mean operative time in isolated procedures was $\mathbf{1 0 3 . 4}$ minutes (SD 6.5). All but one patient had iliosacral screws implanted, 18 had screws in the anterior column, six had plates at the symphysis pubis and $\mathbf{1 2}$ had anterior external fixators. The mean maximum horizontal or vertical displacement was improved from $30.8 \mathrm{~mm}$ (SD 2.7) to a mean of $7.1 \mathrm{~mm}$ (SD 0.7). The reduction was assessed as excellent in ten patients, good in 18 , and fair in the remainder. There was no significant influence on the quality of the reduction caused by obesity $(p=0.34)$, the type of fracture $(p=0.41)$ or delay to surgery $(p=0.83)$.

The frame was shown to be effective, allowing the surgeon to obtain a satisfactory reduction and fixation of acute displaced disruptions of the pelvic ring.

The goal of surgery in pelvic fractures is to obtain the best reduction possible and introduce appropriate fixation without serious complications. ${ }^{1-4}$ Achieving this can be difficult, especially if minimally invasive techniques are used. The three-dimensional shape of the pelvis, its deep location and the relationship to vital structures, together with the multiplanar displacement of the injuries combine to make surgery demanding. In particular, the anatomical reduction and stabilisation of any fracture with percutaneous screws is difficult.

The pioneers of percutaneous stabilisation described several methods of reduction. These include manual reduction or skeletal traction to realign cephalad displacement of the injured hemipelvis, ${ }^{5}$ Schanz pins or external fixator pins placed in the iliac wing to gain rotational control of the pelvic ring, 5,6 a femoral distractor attached to anterior pelvic pins to provide gradual compression or distraction of the posterior ring, ${ }^{5,7}$ and iliosacral screws carefully positioned to effect reduction of a fracture or dislocation. ${ }^{5}$ Anchoring the uninjured hemipelvis to the operating table using a specially designed frame simplifies reduction by providing a stable platform against which the surgeon may manipulate the injured hemipelvis. ${ }^{8}$ However, minimally invasive reduction remains challenging, especially in fractures which are markedly displaced. Reduction and stabilisation often become a complicated team effort with several surgeons, nurses and radiographers working together in attempting to obtain adequate alignment and fixation.

Whether undertaken in an open or a closed manner, surgery remains an exercise in the application of reduction forces to counteract the deformation caused by the injury and the pull exerted by the muscles attached to the displaced fragments. We believed that a device which secures the patient to the operating table, to allow stepwise realignment of the fracture would make surgery easier and more precise. We have developed a frame comprised of two carbon-fibre rings which are attached to the operating table and, by means of steel pins, to the patient (Starr Frame, Limited Liability Corporation, Richardson, Texas). By manipulating the pins and clamping them to the frame, a gradual realignment of the pelvis can be achieved. The complete technique is described elsewhere. ${ }^{9}$ 


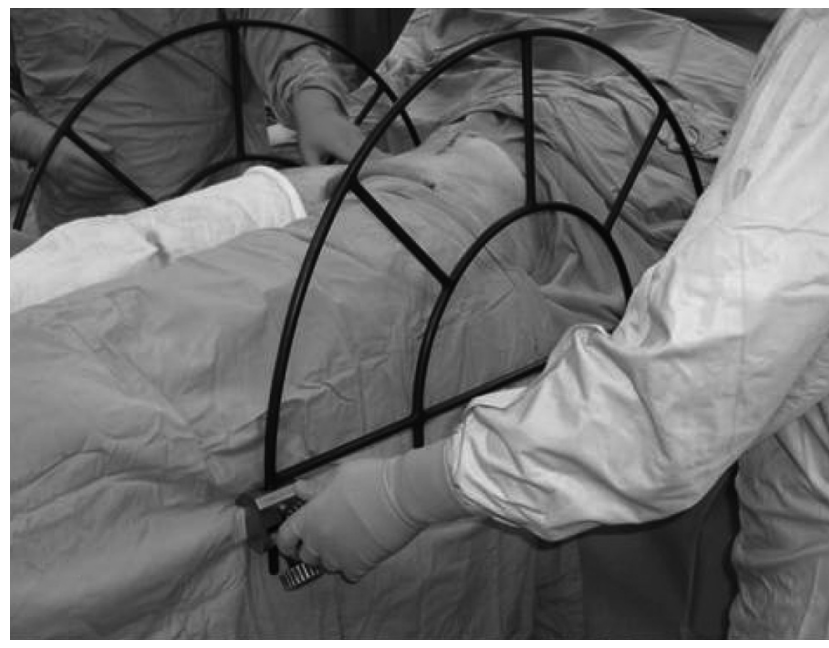

Fig. 1a

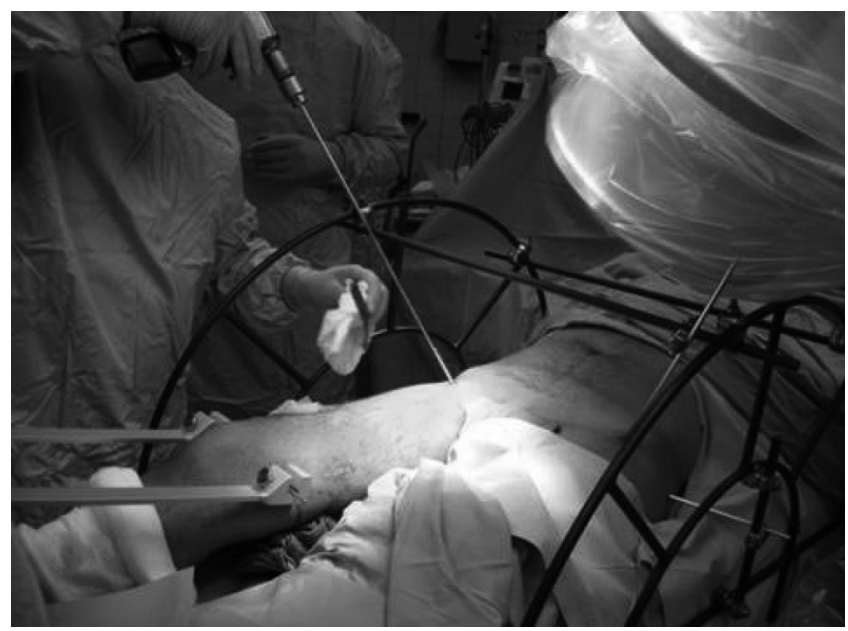

Fig. 1c

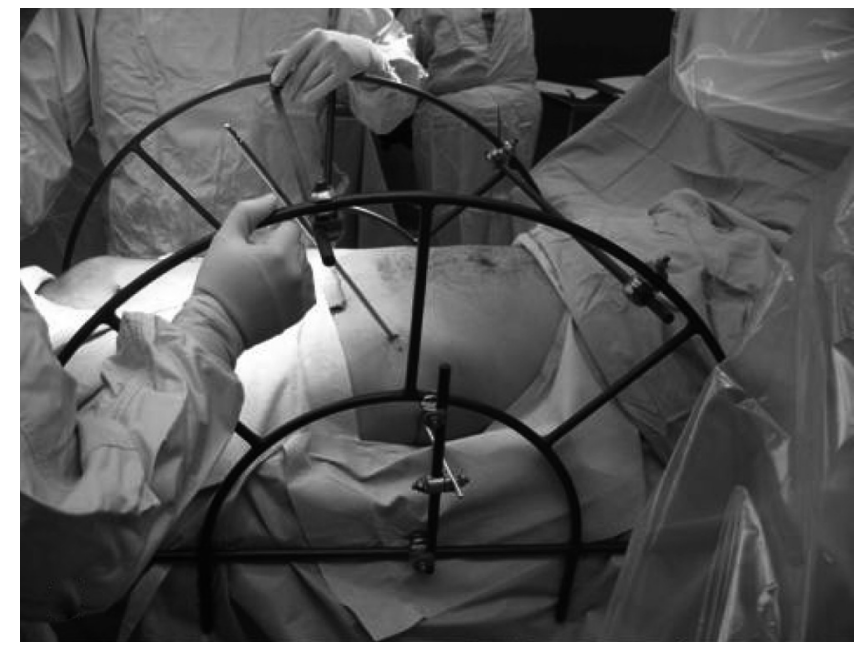

Fig. 1b

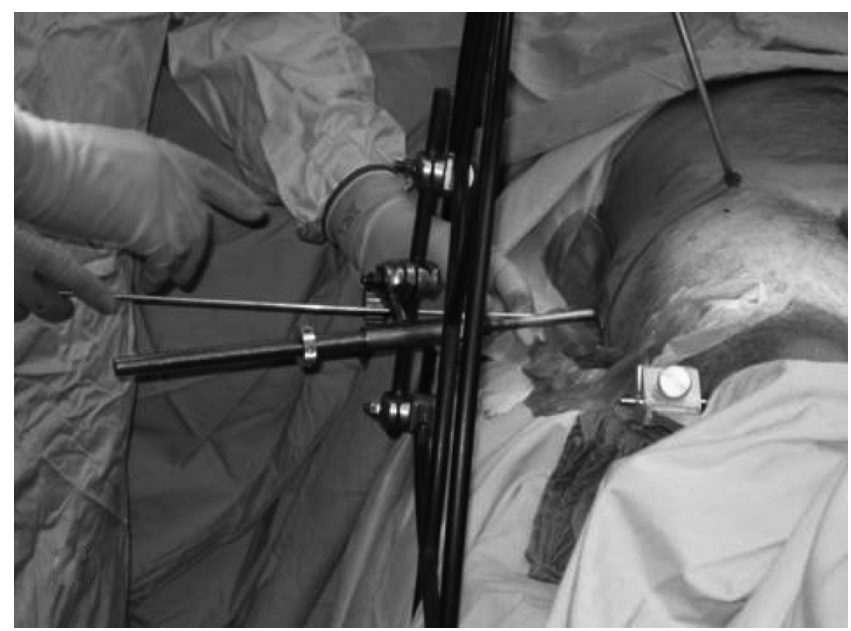

Fig. 1d

Photograph showing a) the reduction frame being attached to the operating table after the patient has been draped, b) multiplanar external fixator pins placed in the uninjured hemipelvis (foreground) and then attached to the frame, c) an external fixation pin being placed at the anterior inferior iliac spine on the injured side and d) reduction has been obtained and locked in place, with placement of posterior fixation.

Commonly, two pins are used on the uninjured side of the pelvis to secure the patient to the frame, which has been clamped on to the operating table (Fig. 1). Vertical displacement of the injury is addressed by applying traction via a skeletal traction pin in the distal femur, attached to a traction bow on the end of the bed. This is supplemented with traction delivered via an external fixation pin placed at the level of the iliac crest in line with the long axis of the sacrum. Anteroposterior (AP) displacement is addressed using an external fixator pin secured to the anterior inferior iliac spine. Once satisfactory reduction has been achieved the pins are locked to the frame and percutaneous fixation of the posterior pelvic ring is performed with the frame in place (Fig. 1). Subsequently, anterior fixation is performed either by an open technique or percutaneously, or by defin- itive external fixation, according to the particular requirements of the fracture.

We began using a prototype of the frame in 2005 , and describe our early experience and the results obtained in the first 35 patients.

\section{Patients and Methods}

The patients had a mean Injury Severity Score ${ }^{10,11}$ of 28 (12 to 57). There were 34 acute fractures and one nonunion. The mean age was 33.5 years (10 to 59). One child aged ten years was included; all the other patients were aged 17 years or more. There were 11 females and 24 males. The mean body mass index (BMI) was 27.6 (SD 1.1), with nine patients having a BMI > 30 (Table I). The fractures were classified according to the sytstem of Young et al. ${ }^{12}$ There were 
Table I. Patient information

\begin{tabular}{|c|c|c|c|c|c|c|c|}
\hline Year & Patient & Gender & $\begin{array}{l}\text { Age } \\
\text { (yrs) }\end{array}$ & $\begin{array}{l}\text { Injury } \\
\text { pattern* }\end{array}$ & $\begin{array}{l}\text { Interval from injury } \\
\text { to operation (days) }\end{array}$ & $\begin{array}{l}\text { Post-operative maximum } \\
\text { displacement }(\mathrm{mm})\end{array}$ & $\begin{array}{l}\text { Adequacy of } \\
\text { reduction }\end{array}$ \\
\hline \multirow[t]{3}{*}{2005} & 1 & $M$ & 53 & VS & 3 & 10 & Good \\
\hline & 2 & M & 32 & VS & 1 & 4 & Good \\
\hline & 3 & $M$ & 52 & VS & 4 & 8 & Good \\
\hline \multirow[t]{10}{*}{2006} & 4 & $\mathrm{~F}$ & 32 & VS & 4 & 5 & Good \\
\hline & 5 & $M$ & 52 & VS & 1 & 13 & Fair \\
\hline & 6 & $M$ & 44 & APC 2 & 4 & 2 & Excellent \\
\hline & 7 & $\mathrm{~F}$ & 19 & LC 2 & 5 & 3 & Excellent \\
\hline & 8 & $M$ & 41 & APC 3 & 3 & 8 & Good \\
\hline & 9 & $\mathrm{~F}$ & 21 & VS & 4 & 6 & Good \\
\hline & 10 & $M$ & 31 & VS & 7 & 2 & Excellent \\
\hline & 11 & M & 40 & VS & 4 & 15 & Fair \\
\hline & 12 & $M$ & 17 & APC 3 & 2 & 11 & Fair \\
\hline & 13 & $M$ & 18 & APC 3 & 1 & 4 & Good \\
\hline \multirow[t]{14}{*}{2007} & 14 & $M$ & 54 & APC 3 & 120 nonunion & 16 & Fair \\
\hline & 15 & $\mathrm{~F}$ & 20 & VS & 2 & 8 & Good \\
\hline & 16 & $F$ & 44 & APC 3 & 6 & 3 & Excellent \\
\hline & 17 & $M$ & 24 & VS & 4 & 10 & Good \\
\hline & 18 & $\mathrm{~F}$ & 25 & LC 2 & 2 & 4 & Excellent \\
\hline & 19 & $\mathrm{~F}$ & 45 & VS & 14 & 10 & Good \\
\hline & 20 & $M$ & 26 & VS & 7 & 5 & Good \\
\hline & 21 & $M$ & 17 & APC 3 & 5 & 7 & Good \\
\hline & 22 & $\mathrm{~F}$ & 21 & VS & 12 & 11 & Fair \\
\hline & 23 & $M$ & 27 & VS & 5 & 14 & Fair \\
\hline & 24 & $M$ & 39 & VS & 5 & 15 & Fair \\
\hline & 25 & $M$ & 59 & VS & 0 & 4 & Excellent \\
\hline & 26 & $\mathrm{~F}$ & 50 & VS & 0 & 3 & Excellent \\
\hline & 27 & $\mathrm{~F}$ & 18 & LC 3 & 2 & 6 & Good \\
\hline \multirow[t]{8}{*}{2008} & 28 & $M$ & 17 & APC 3 & 5 & 4 & Excellent \\
\hline & 29 & $M$ & 26 & LC 3 & 5 & 8 & Good \\
\hline & 30 & $\mathrm{~F}$ & 44 & LC 3 & 4 & 4 & Good \\
\hline & 31 & $M$ & 10 & LC 3 & 7 & 4 & Excellent \\
\hline & 32 & $M$ & 35 & APC 3 & 4 & 5 & Good \\
\hline & 33 & $M$ & 30 & VS & 3 & 7 & Good \\
\hline & 34 & $M$ & 59 & VS & 16 & 5 & Good \\
\hline & 35 & $M$ & 30 & APC 3 & 4 & 4 & Excellent \\
\hline
\end{tabular}

* VS, vertical shear, APC, anteroposterior compression (type 2 or 3); LC, lateral compression (type 2 or 3 )

19 vertical shear type injuries, nine AP compression type III, one AP compression type II, four lateral compression type III and two lateral compression type II injuries. For analysis these were divided into two subgroups of 19 vertical shear and 16 compression type injuries. This distinction between vertical shear and compression fractures was made because the vertical injuries required reduction forces mainly in the cephalad to caudad direction, whereas those in the compression group required primarily side-to-side reduction.

Radiographic review. Each patient had AP, inlet and outlet pelvic radiographs both pre- and post-operatively. The displacement of the fracture was measured using pixel calibration with a standard ruler from the Picture Archive Communication system (PACS) (MagicWeb, Seimens Inc, New York, New York). Each measurement was done by two independent observers (KAL, BPB) and the mean calculated. In patients where several pre-operative series were performed, that showing most displacement was used for measurement.

Two methods were used to quantify displacement of the pelvic ring. First, the method described by Keshishyan et al, ${ }^{13}$ later reported by Smith et al, ${ }^{14}$ for describing displacement in paediatric disruption of the pelvic ring was used. This method uses the AP pelvic view only, and in skeletally immature patients records the distance from the inferior aspect of the sacroiliac joint to the contralateral triradiate cartilage. In our adult patients we measured the distance from the inferior aspect of the sacroiliac joint to the inferior aspect of the teardrop, which is accepted as a reliable radiographic marker on films of the pelvis in adults. ${ }^{15}$ These measurements were evaluated in two ways, the first being to subtract one side from the other, yielding a pelvic asymmetry value (X-Y). The Deformity Index, which takes obliquity of the exposure into account, was the cal- 


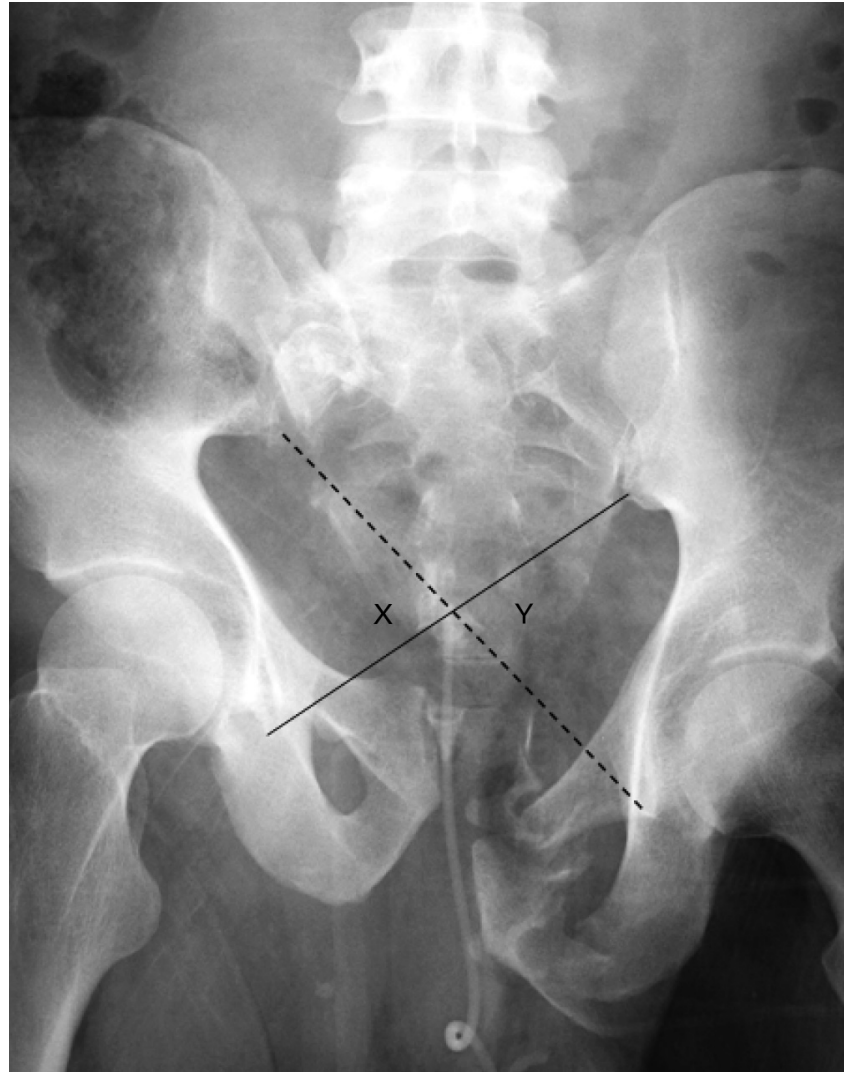

Fig. 2

Radiograph showing measurement of displacement asymmetry $(X-Y)$, and deformity index $(X-Y / X+Y)$.

culated $(\mathrm{X}-\mathrm{Y} / \mathrm{X}+\mathrm{Y}) \cdot{ }^{13}$ An example of these measurements is shown in Figure 2.

We recognised that the Keshishyan system could quantify the displacement well in some patients while minimising the measured displacement in others. For vertical displacement, this technique accurately quantifies the difference between the hemipelves (Fig. 2), but where the injury involves primary widening of the pelvic ring, it underrecords the displacement (Fig. 3).

A second method was carried out as follows. A horizontal line was drawn across the superior endplate of the fifth lumbar vertebra as a reference. Using this line as the direction for horizontal measurements, or perpendicular to this line for vertical measurements, the maximum displacement of the anterior and posterior pelvic ring was measured. The displacement recorded was either across a fracture or disruption (sacral fracture, pubic ramus fracture, sacroiliac joint disruption, symphysis disruption), or between two displaced normal bony landmarks such as the iliac crests. This was repeated for all three pre-operative views (AP, inlet, outlet). Measurements were taken from the same anatomical locations on the post-operative films. For each patient the displacement was quantified using the maximum pre- and post-operative measurement from the six

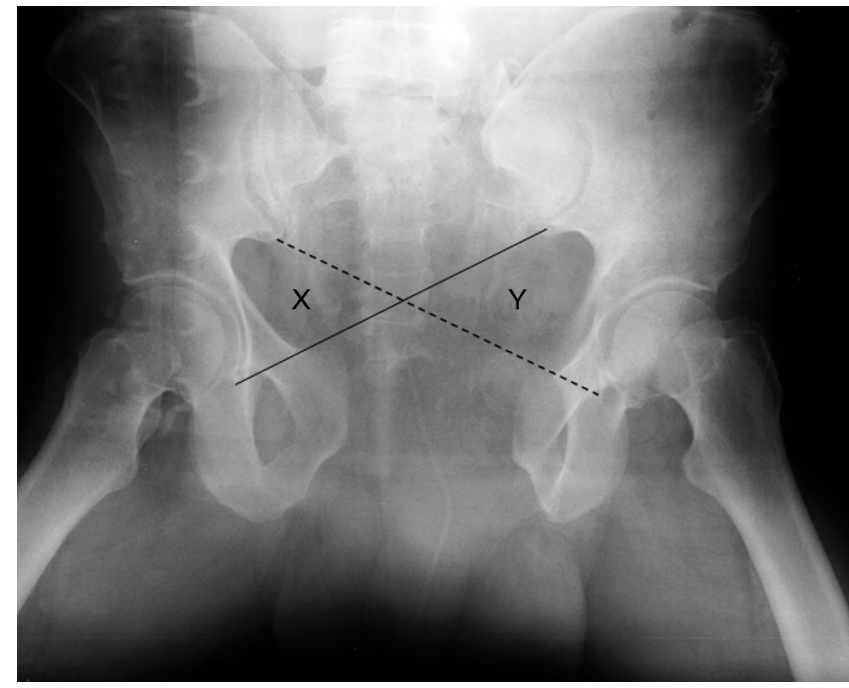

Fig. 3

Radiograph showing with this open-book type injury, $X$ and $Y$ are nearly equal despite gross displacement of the pelvic ring.

taken. Examples are shown in Figures 4 and 5. The final reduction for each patient was graded according to the method of Tornetta and Matta, ${ }^{16}$ where excellent was a residual displacement of $0 \mathrm{~mm}$ to $4 \mathrm{~mm}$; good, $4 \mathrm{~mm}$ to $10 \mathrm{~mm}$; fair, $10 \mathrm{~mm}$ to $20 \mathrm{~mm}$ and poor, a residual displacement exceeding $20 \mathrm{~mm}$.

Procedure. The use of skeletal leg traction, as well as the number of external fixator pins used for stabilisation and reduction, was recorded. The fixation required was noted including the position and side of all iliosacral screws, column and ramus screws, the use of the lateral compression-type II screw stabilisation method with screw placement down the column of bone extending from the anteroinferior iliac spine toward the posteroinferior iliac spine, ${ }^{17}$ symphysis plates and anterior external fixators.

Statistical methods. All descriptive statistics were tabulated using SAS JMP v 7 software (SAS Institute Inc., Cary, North Carolina). Fisher's exact test was used to test the statistical significance of categorical variables, and Student's $t$-test for continuous variables. Statistical significance was set at a $\mathrm{p}$-value $\leq 0.05$.

\section{Results}

For the 34 acute injuries, the mean delay to surgery was 4.6 days ( 0 to 16 ). In all, ten patients had some additional procedure under the same anaesthetic. Of those who had isolated pelvic reduction and fixation, the mean time in the operating theatre, including induction and reversal of the anaesthesia was 103.4 minutes (SD 6.5) and the mean fluoroscopy time was 11.2 minutes (SD 0.9).

For reduction, three external fixator pins were used most frequently, with four pins required in only three patients. Skeletal traction was used in all but nine 


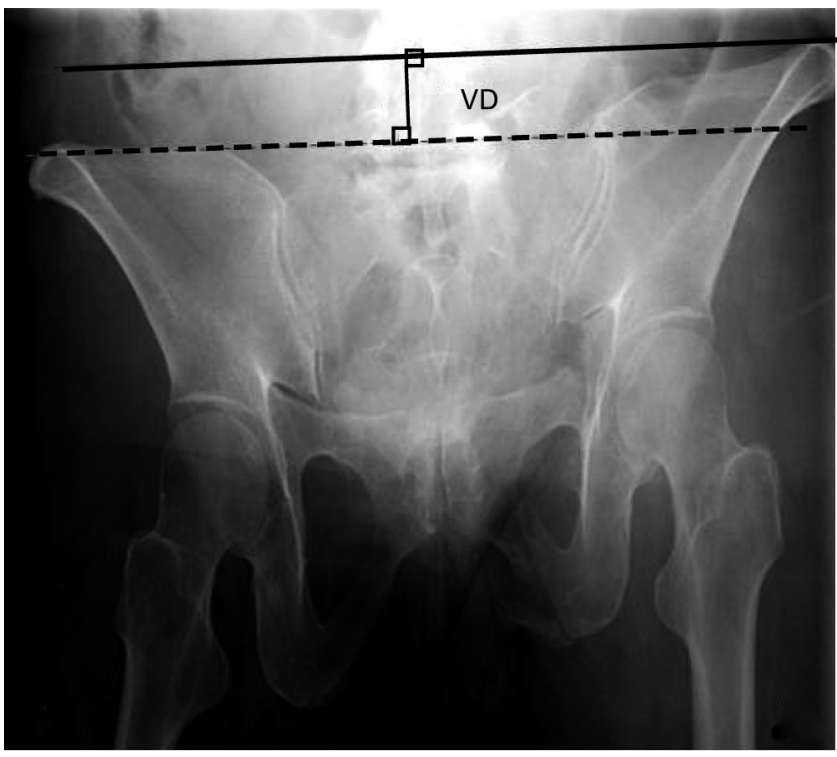

Fig. 4a

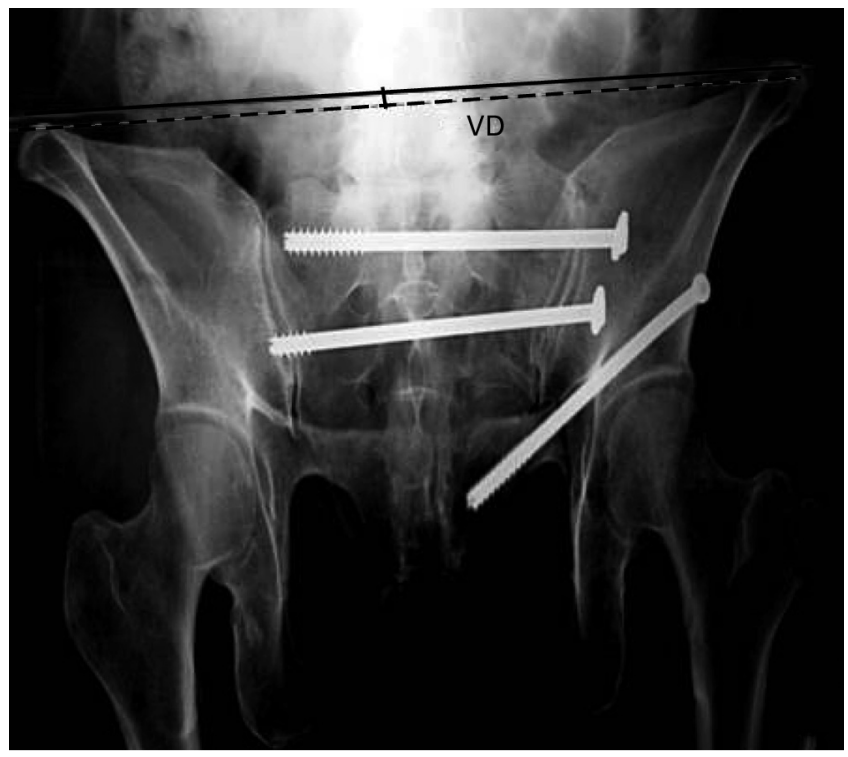

Fig. $4 b$

Radiograph showing a) vertical displacement (VD) is the distance between the top of the iliac crests and a line perpendicular to the L5 reference line and $b$ ) the corrected displacement on the post-operative radiograph in the same patient.

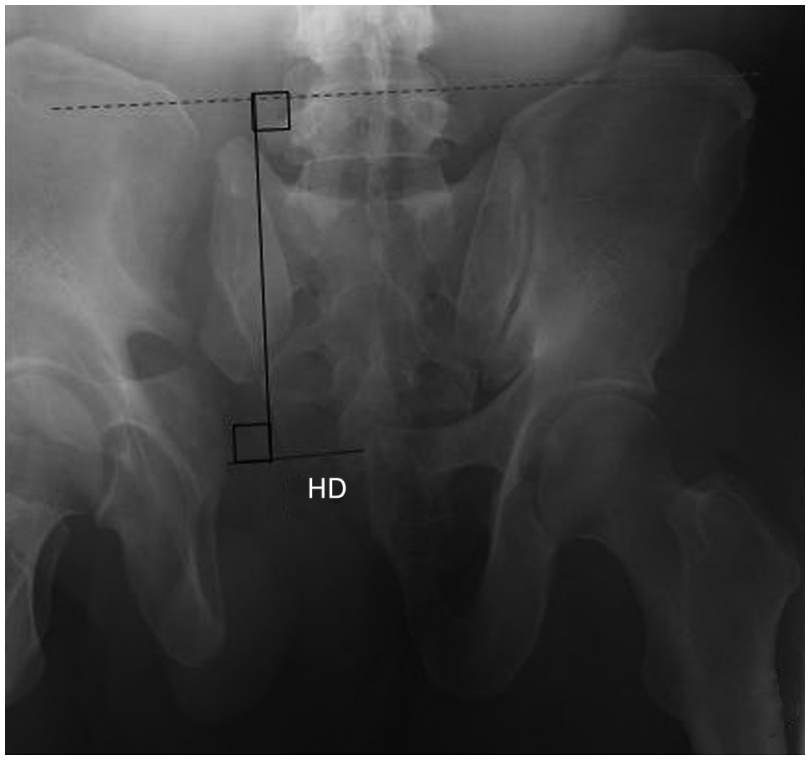

Fig. $5 a$

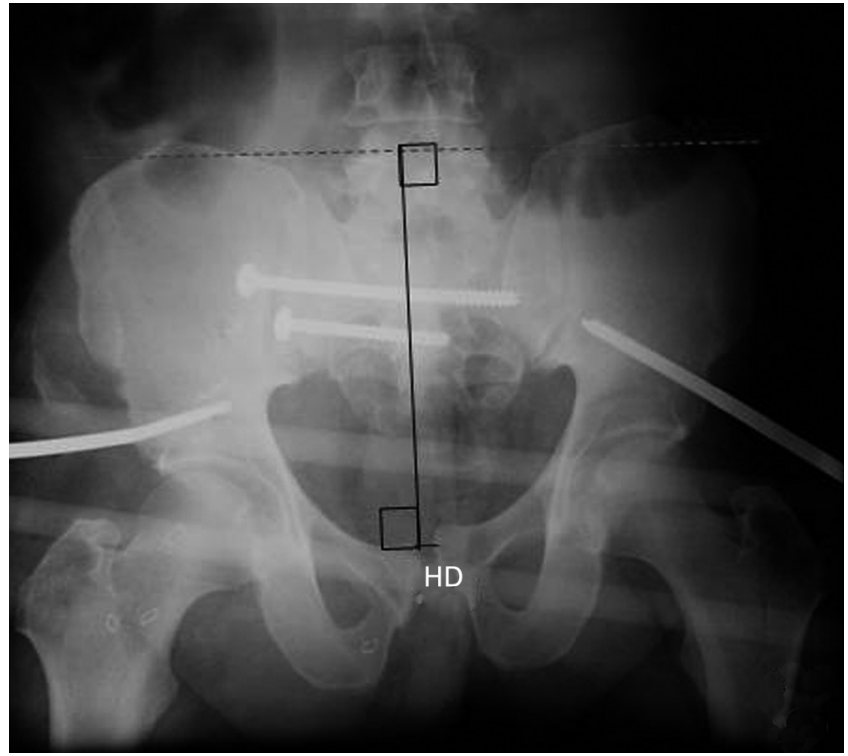

Fig. $5 b$

Radiograph showing a) horizontal displacement (HD) measured parallel to the L5 reference line at the symphysis pubis and b) the correction obtained in same patient post-operatively.

patients, and employed bilaterally in one. All patients except one with the APC compression type II disruption had iliosacral screws placed posteriorly, with a total of 56 screws used. Three patients had a screw placed in the lateral compression type II position where the screw is placed down the column of bone extending from the anterior inferior iliac spine toward the posterior inferior iliac spine. ${ }^{17}$ In all, 18 patients required anterior column/ ramus screws, and six patients needed plates to the sym- physis pubis. A total of 12 patients were left with anterior external fixators in situ.

The evaluation of pre- and post-operative displacements in the acutely injured patients is summarised in Table II.

The results show that our patients presented with marked displacement which we were able to improve using the reduction frame. The adequacy of reduction for each patient according to the Tornetta and Matta classification ${ }^{16}$ is listed in Table I. We were able to obtain an excellent 
Table II. Maximum displacement as measured using the two methods on pre- and post-operative anteroposterior pelvic radiographs

\begin{tabular}{|c|c|c|c|}
\hline Measurement & Pre-operatively & Post-operatively & Correction obtained \\
\hline Mean asymmetry (X-Y) in mm (range) & (4 to 55.1 ) & (0.04 to 15.7$)$ & $21.2(0.6$ to 51.05$)$ \\
\hline Mean deformity index $(\mathrm{X}-\mathrm{Y} / \mathrm{X}+\mathrm{Y})$ (range) & $0.094(0.014$ to 0.196$)$ & $0.019(0$ to 0.059$)$ & $0.075(0.001$ to 0.171$)$ \\
\hline Mean maximum horizontal or vertical displacement in $\mathrm{mm}$ (range) & (10.6 to 95$)$ & $7.1 \quad(2.1$ to 15.9$)$ & $23.7(5.9$ to 86.6$)$ \\
\hline
\end{tabular}

reduction in ten patients, a good reduction in 18 and a fair reduction in seven. The mean maximum post-operative absolute displacement was $7.1 \mathrm{~mm}$ (SD 0.7) and the mean asymmetry on the AP view was $5.2 \mathrm{~mm}$ (SD 0.7).

In the acute fractures the mean delay to surgery was similar both in fractures that were rated as excellent or good reductions at 4.5 days (SD 0.7 ), and in those with acceptable reductions with a mean of 4.8 days (SD 1.6). This difference lacked statistical significance $(t$-test, $\mathrm{p}=0.83)$. One third of the obese patients (three of nine) had a fair reduction as did four of 26 non-obese patients, but again this difference was not statistically significant (Fisher's exact test, $\mathrm{p}=0.34$ ). There were slightly fewer excellent or good reductions in the vertical shear group (14 of 19) than in the compression group (14 of 16), but this lacked statistical significance $(\mathrm{p}=0.41)$.

\section{Discussion}

Surgical treatment of displaced disruption of the pelvic ring is widely recognised as challenging. ${ }^{1-4}$ Although formal open reduction and internal fixation has been advocated by several authors for the treatment of displaced injuries, ${ }^{1,3,18}$ the use of percutaneous techniques, especially in the posterior pelvic ring, has gained wide acceptance. , 19-23 $^{-23}$

Assessment of the adequacy of the reduction has been used widely as an outcome measure..$^{6,17,18,23-27}$ despite this, a standardised method of measuring displacement in these injuries in adults has yet to be outlined, making comparisons between reports unsatisfactory. Therefore, we chose to use the method modified from the description of Keshishyan et $\mathrm{al}^{13}$ for measuring radiographs of injuries to the pelvic ring in children. This revealed a mean improvement in cross-diameter asymmetry on the AP pelvic radiograph from $26.4 \mathrm{~mm}$ to $5.2 \mathrm{~mm}$. We also developed a system of measuring absolute displacement in the vertical and horizontal planes on pelvic radiographs. The inter- and intra-observer reliability of both of these methods has yet to be tested, and there are inherent sources of error due to lack of adjustment for magnification.

The grading of measurement of the adequacy of the reduction described by Tornetta and Matta ${ }^{16}$ lacks firm basis for its thresholds. However, it is the most commonly used system to grade the radiographic outcome, despite lack of consistency in how the measurements are taken. ${ }^{16,18,23,26,28}$ Based on this system, the outcome was excellent and good in 28 of our patients $(80 \%)$, even though considerable pre-operative displacement had been present, which is similar to that described in previous series. ${ }^{5,16,21,29}$ Both methods of assessment of reduction were performed comparing the pre- and post-operative radiographs and found reliable improvement in the radiographic displacement.

The difficulty encountered in obtaining reduction limits the use of percutaneous reconstruction in the treatment of pelvic fractures. Instrumentation that simplifies reduction should encourage the use of minimally invasive techniques, provided the reduction is adequate. The problems associated with making a direct comparison of our results with previously published work means that we retain some uncertainty regarding our findings and consider that the results should be considered as part of a feasibility study.

One variable that was not assessed was the surgeon's impression of the ease of reduction, although we accept that such a measurement would be difficult to make objectively. However, our ability to obtain an acceptable reduction was not significantly associated with delay to surgery when using the frame. Likewise neither obesity of the patient nor the fracture type were associated with the adequacy of the reduction in this series.

The ability to maintain a stable reduction of the pelvic ring using the pelvic reduction frame would enable computer-assisted navigation to be used to finalise the anatomical reduction. ${ }^{30}$ With the uninjured side and the displaced sides of the pelvis locked to the frame, fluoroscopic images could be gathered for navigation without concern for movement of fracture fragments and subsequent misplacement of fixation.

This pelvic reduction frame has shown its value in obtaining effective reduction and fixation of displaced pelvic ring disruptions. Early experience with this prototype has yielded promising results.

The author or one or more of the authors have received or will receive benefits for personal or professional use from a commercial party related directly or indirectly to the subject of this article.

One of the authors, Dr Starr, may receive royalties from a commercial entity from the sale of the device whch is the subject of the manuscript. Dr Lefaivre, $\mathrm{Dr}$ Barker, Dr Overturf and Dr Reinert have certified that they no commercial associations.

\section{References}

1. Tornetta P 3rd, Templeman DC. Expected outcomes after pelvic ring injury. Instr Course Lect 2005;54:401-7.

2. Templeman DC, Simpson T, Matta JM. Surgical management of pelvic ring injuries. Instr Course Lect 2005;54:395-400.

3. Matta JM, Saucedo T. Internal fixation of pelvic ring fractures. Clin Orthop 1989;242:83-97.

4. Mears DC, Rubash HE. External and internal fixation of the pelvic ring. Instr Course Lect 1984;33:144-58.

5. Routt ML Jr, Kregor PJ, Simonian PT, Mayo KA. Early results of percutaneous iliosacral screws placed with the patient in the supine position. $J$ Orthop Trauma 1995;9:207-14 
6. Bellabarba C, Ricci WM, Bolhogner BR. Distraction external fixation in lateral compression pelvic fractures. J Orthop Trauma 2006;20 (1 Suppl):7-14.

7. Gardner MJ, Nork SE. Stabilization of unstable pelvic fractures with supraacetabular compression external fixation. J Orthop Trauma 2007;21:269-76.

8. Matta JM, Yerasimides JG. Table-skeletal fixation as an adjunct to pelvic ring reduction. J Orthop Trauma 2007;21:647-56.

9. Lefaivre KA, Starr AJ, Reinert CM. Reduction of displaced pelvic ring disruptions using a pelvic reduction frame. J Orthop Trauma 2009;23:299-308.

10. Baker SP, O'Neill B. The injury severity score: an update. J Trauma 1976:16:882-5

11. Baker SP, O'Neill B, Haddon W Jr, Long WB. The injury severity score: a method for describing patients with multiple injuries and evaluating emergency care. $J$ Trauma 1974; 14:187-96

12. Young JW, Burgess AR, Brumback RJ, Poka A. Pelvic fractures: value of plain radiography in early assessment and management. Radiology 1986;160:445-51.

13. Keshishyan RA, Rozinov VM, Malakhov OA, et al. Pelvic polyfractures in children: radiographic diagnosis and treatment. Clin Orthop 1995;320:28-33.

14. Smith W, Shurnas $\mathbf{P}$, Morgan $\mathbf{S}$, et al. Clinical outcomes of unstable pelvic fractures in skeletally immature patients. J Bone Joint Surg [Am] 2005;87-A:2423-31.

15. Bowerman JW, Sena JM, Chang R. The teardrop shadow of the pelvis, anatomy and clinical significance. Radiology 1982;143:659-62.

16. Tornetta P III, Matta JM. Outcome of operatively treated unstable posterior pelvic ring disruptions. Clin Orthop 1996;329:186-93.

17. Starr AJ, Walters JC, Harris RW, Reinert CM, Jones AL. Percutaneous screw fixation of fractures of the iliac wing and fracture dislocations of the sacro-iliac joint (OTA types 61-B2.2 and 61-B2.3, or Young-Burgess "Lateral compression type II" pelvic fractures). J Orthop Trauma 2002;16:116-23.

18. Kabak S, Halici $\mathbf{M}$, Tuncel $\mathbf{M}$, et al. Functional outcome of open reduction and internal fixation for completely unstable pelvic ring fractures (type C): a report of 40 cases. J Orthop Trauma 2003;17:555-62.
19. Giannoudis PV, Tzioupis CC, Pape H-C, Roberts CS. Percutaneous fixation of the pelvic ring: an update. J Bone Joint Surg [Br] 2007;89-B:145-54.

20. Gansslen A, Hufner T, Krettek C. Percutaneous iliosacral screw fixation of unstable pelvic injuries by conventional fluoroscopy. Oper Orthop Traumatol 2006;18:225-44

21. Routt ML Jr, Nork SE, Mills WJ. Percutaneous fixation of pelvic ring disruptions. Clin Orthop 2000;375:15-29.

22. Keating JF, Werier J, Blachut PA, et al. Early fixation of the vertically unstable pelvis: the role of iliosacral screw fixation of the posterior lesion. J Orthop Trauma 1999:13:107-13

23. Moed BR, Geer BL. S2 iliosacral screw fixation for disruptions of the posterior pelvic ring: a report of 49 cases. J Orthop Trauma 2006;20:378-83.

24. Arazi M, Kutlu A, Mutlu M, Yel M, Safa Kapiciglu MI. The pelvic external fixation: the mid-term results of 41 patients treated with a newly designed fixator. Arch Orthop Trauma Surg 2000;120:584-6.

25. Lindahl J, Hirvensalo E, Bostman 0, Santavirta S. Failure of reduction with an external fixator in the management of injuries of the pelvic ring: Iong-term evaluation of 110 patients. J Bone Joint Surg [Br] 1999;81-B:955-62.

26. McCarthy ML, MacKenzie EJ, Bosse MJ, et al. Functional status following orthopedic trauma in young women. J Trauma 1995;39:828-36.

27. Reilly MC, Zinar DM, Matta JM. Neurologic injuries in pelvic ring fractures. Clin Orthop 1996;329:28-36.

28. Holtslag H, Post MW, Lindeman E, Van der Werken C. Long-term functional health status of severely injured patients. Injury 2007;38:280-9.

29. Routt ML Jr, Nork SE, Mills WJ. High-energy pelvic ring disruptions. Orthop Clin North Am 2002;33:59-72.

30. Mosheiff R, Khoury A, Weil Y, et al. First generation computerised fluoroscopic navigation in percutaneous pelvic surgery. J Orthop Trauma 2004;18:106-11. 